\title{
A Study on the Influence of Yu Xin's "Bu Xu Ci” on Literati Taoist Literary Creation
}

\author{
Mengmeng Zhou \\ College of Liberal Arts \\ Northwest University for Nationalities \\ Lanzhou, Gansu, China 730030
}

\begin{abstract}
Taoist unique literati $\mathrm{Bu} \mathrm{Xu} \mathrm{Ci}$ was founded from Yu Xin's "Ten Taoist Bu Xu Ci" in the Northern Zhou Dynasty. Although the origin is the Tao $\mathrm{Qu} \mathrm{Bu} \mathrm{Xu}$, it reflects the creation feature of literati and weakens the shackles of Taoist rituals in writing function, showing very different appearance from the Taoist Bu Xu Ci, which not only determines the future development direction of $\mathrm{Bu} \mathrm{Xu} \mathrm{Ci}$, but also greatly influences the ideological content and artistic features of Qing $\mathrm{Ci}$ and $\mathrm{Nv}$ Guan Ci that rose in the Tang Dynasty.
\end{abstract}

\section{Keywords-Yu Xin; Bu Xu Ci; literati; ritual literature}

\section{INTRODUCTION}

There are many literati in the Northern Dynasties. The creation works of literati permeated with Taoism also have a large number, but with few works about $\mathrm{Bu} \mathrm{Xu} \mathrm{Ci}$ conserved. During the Northern Dynasties, the first appearance of the literati $\mathrm{Bu} \mathrm{Xu} \mathrm{Ci}$ weakened the shackles of Taoist rituals in writing function, showing the utterly different appearance from the Taoist $\mathrm{Bu} \mathrm{Xu} \mathrm{Ci}$, thus opening the prelude of literati's creation of $\mathrm{Bu} \mathrm{Xu} \mathrm{Ci}$. It greatly influenced the ideological contents and artistic features of Qing $\mathrm{Ci}$ and $\mathrm{Nv}$ Guan $\mathrm{Ci}$ that rose in the Tang Dynasty. This article lists $\mathrm{Bu} \mathrm{Xu} \mathrm{Ci}$ writers who has the greatest impact on the history of Taoist literature in the Northern Dynasties, discusses the ideology contents and artistic characteristics of $\mathrm{Yu}$ Xin's $\mathrm{Bu} \mathrm{Xu} \mathrm{Ci}$. As a rare Taoist ritual literature created by literati during the Northern Dynasties, Yu Xin's Bu Xu Ci is not only permeated with strong Taoist ideology, but also shows its unique color in literary form, language skills and ideological thrust.

\section{The IdeOlogical Content of Yu XIN'S "Bu Xu CI"}

Yu Xin (513-581), whose style name is Zishan, was born in Xinye of Nanyang. He was an important litterateur and poet in the Northern Zhou Dynasty. He was well-read and grew up with superhuman talent and followed his father to enter the palace and then became the reading partner of Prince Xiao Tong; later he was forced to stay in the North area because of war and his own poetic talent, so that the content and style of his poetry changed greatly. Yu Xin, with his outstanding poems and special experiences finally became a master who combined both advantages from north to south, and left many outstanding literary works, among which the most famous Taoist ritual work is "Taoist $\mathrm{Bu} \mathrm{Xu} \mathrm{Ci}$ ".
After entering the official career in the Northern Dynasty, $\mathrm{Yu}$ Xin was friendly with TengWang $\mathrm{Yu}$ Wenyou and ZhaoWang Yu Wenzhao, who both believe in Taoism. Yu Xin and Yu Wenzhao even directly create Taoist poem, so that this group of $\mathrm{Bu} \mathrm{Xu} \mathrm{Ci}$ should be the product after $\mathrm{Yu}$ Xin entered the Zhou Dynasty under the influence of the atmosphere of advocating Taoism. Its theme still closely related to Taoism, but it not simply preached religious beliefs. It carried the literati's emotions, and its nature has also separated from the Keyi of Lingbao.

\section{A. Propagate Immortal Thoughts, God Thought, Express the Consciousness of Admiring the Immortal}

Use heavy and thick colors to describe the beauty and the comfort of the gods' land, the happy life the gods have, emphasize the mystery of gods' magic arts and power, and express his desire to cultivate himself according to the Taoism and become the immortal and his admiration for the immortal, such as:

"Huiyun suiwuqu. Liushui zhugexuan. Shisui xiangrufan. Zhifang cuisilian. Tingluan yanyaoshui. Guilu shanghongtian." ${ }^{[1]}$ (IV)...

The gods' land is magnificent. All the creatures dance together and all things are harmonious, wonderful and extraordinary, which are great temptation for the Taoists.

Yu Xin used Taoist allusions and terms very often. He used a large number of references for the allusions and historical facts of practice to immortality. According to the statistics of $\mathrm{Yu}$ Xin's works, many of them are closely related to the content of becoming a god, as many as 35 cases. The main characters of the gods are "Yuanshi Tianzun", "Huangdi", "Xiwangmu", "Rongchenggong", "Ningfengzi", "Anqisheng", "Wangziqiao", "Qiong Shu", "Hanwudi", "Geyou", "Wangyao", "Huainanwang Liuan", "Wanglie", "Shenwentai", "Jiexiang" and so on. Most are from the miscellaneous biography and historical data that collect a large number of mythologies. Only the Taoist classics include: Lao Zi's "Tao Te Ching" from Spring and Autumn Period, "Taiping Scripture" from the middle and late period of the Eastern Han Dynasty, Moralist Ge Hong's "Bao Puzi" in the Eastern Jin Dynasty, Taoist Tao Hongjing's "Zhen Gao" and "Zhen Ling Wei Ye Tu" in the Southern Dynasties and so on. Besides, there is some Immortal Biography: "the Tales of Immortals" 
with many bizarre stories, "Liexian Zhuan" concerning gods' deeds of the ancient Han, "Hanwudi Neizhuan" with slight description of military affairs but detailed description of the immortal practice.

\section{B. Praised the Greatness of Gods' Magic, Expressed the Longevity Desire}

"Haiji rengchengji, Киуи hиапzиоуи" [1] followed the legend of "Duanjiao xuluan" and that Ge Xuan can make the dead fish re-resurrect in immortal biography, not only embodying Yu Xin's admiration for gods' magic, but also embodying the hope that good things can survive forever and the individual life can live eternally. In addition, he also talked a lot about the experience of opening the stove for alchemy according to his own experience, "Chengdan xuzhujie, Kesui yongludao". [1] Correspondingly, the poem also involves various immortal ways for different people, among which the medicine food is a way to become god that $\mathrm{Yu}$ Xin advocates greatly. The poem mentioned more than ten kinds of god's medicine, such as "Shisui", "Jiuzhi", "Danwan", "Yuliu", "Zhushi", "Yurong", "Peach", "Pear", "Apricot", "Jujube", "Dan" and so on.

\section{Proposes the Bu Xu Ritual's Religious Function of Averting Calamities and Praying for Blessings}

First it narrates the ritual process, and then the ritual function and integrates them. Such as the first poem:

"Huncheng kongjiaoli, yuanshi zhengtukai. Chiyulingwenxia, zhuling zhenqilai. Zhongtian jiulongguan, daojing bafengtai. Yundu xuangexiang, xingyi kongdianhui. Qingyi shangshaoshi, tongzi xiangpenglai. Xiaoyao wensihui, shuhu dusanzai." ${ }^{[1]}$

It records the preaching of Taoist scriptures by Tianzun, the Taoist $\mathrm{Bu} \mathrm{Xu}$, and then the imaginary dreamland, which are exactly the same with Taoism $\mathrm{Bu} \mathrm{Xu}$ ritual recorded in Taoism scriptures. In the end, it makes the final finishing and indicates that all the rituals are to avert calamities and pray for blessings, take across sentient beings universally. The religious color is very distinct and the religious themes are also very clear.

\section{Describe His Subtle Spiritual Journey Full of Twists and Turns}

He truly believes the existence of gods, admires the immortal, thinks of reality rationally, finds out the difficulty in becoming the immortal, then criticizes the absurdity of the emperor's belief; at last expresses his desire to live in seclusion under the cloak of Taoist immortals. The spiritual journey not only is the change of his attitudes towards the Taoist belief, but also the process that his strong thinking of homeland gradually transforms into forgetting the world and living in the seclusion over time.

By the words of "Fengfang de zhujin. Hanwu duo jiaoman, huainan bu xiaoxin. Penglai ru haidi, hechu ke zhuixun." [1], he expressed the sarcasm for governor's extremely absurdity and blind admiration for immorality. The poet believed that the socalled Penglai fairyland is only a kind of illusory ideal existence. The governor was ignorant and even spent the national strength, human resources and material resources in pursuing a fine bubble, full of ironic sense.

If the governors spend all the time and energy in the pursuit of wonderland beyond the human world, and ignore the lives of people, then one day, the state will fall into the decline until the crisis of extinction. The poet's understanding is profound and deep, naturally involving the deep concern for the country's future and people's destiny, as in the eighth poem: "Shangyuan Fengyu san, Zhongtian Gechui fen. Lingjia Qianxun shang, Kongxiang Wanli wen." ${ }^{[1]}$ This statement is just right. This poem makes good use of "San", "Fen"and other words, suggesting the country's gloomy future. Besides, the author had witnessed the tragic event of country destroyed and home lost, so the pain of subjugation, sorrow of homelessness rushed to his mind again and hid in the poem full of grief feelings. It expands the expression content of "Bu Xu" $\mathrm{Ci}$, so as to make it have the aspiration function of pointing to the reality; meanwhile it improves the meaning of the poem style, makes it reach a new height, laying a solid foundation for the independence of $\mathrm{Bu} \mathrm{Xu} \mathrm{Ci}$ in the later ages especially the Tang Dynasty.

Yu Xin's ultimate desire is "Seclusion". The god belief has already been disillusioned, and as the adherent of former dynasty, he was no longer infatuated with gods' fantasy imagination as many literati and Taoists, also not pursued fame and career, but pointed his life to the way of seclusion in a rational posture. This decision was put in the last poem: "Chendan xu zhujie, kesui yong ludao. Wufang yinshiqu, jishi xianren tao". ${ }^{1]}$ This is the decision under careful consideration after he experienced the long spiritual trip in the former poems.

\section{THE FORM CHARACTERISTIC OF YU XIN'S "BU XU CI"}

Regardless of the theme, from the perspectives of the structure and prosody rhythm of $\mathrm{Bu} \mathrm{Xu} \mathrm{Ci}$, it has already been a typical form of poem, and its artistic representation also has the characteristics of poetry. These $\mathrm{Bu} \mathrm{Xu} \mathrm{Ci}$ from Taoist scriptures show rich imagination, use gorgeous language and rhetorical devices like exaggeration and metaphor to perfectly represent the mysterious religious rituals, the illusory ethereal fairyland and the gods' good lives admired by others. Every place is filled with the romantic atmosphere. At the same time, out of the singing requirements, $\mathrm{Bu} \mathrm{Xu} \mathrm{Ci}$ particularly stresses syllable fluency, coherent rhyme, and even antithetical parallelism, which are in line with the pure poetry literature.

$\mathrm{Yu}$ Xin's $\mathrm{Bu} \mathrm{Xu} \mathrm{Ci}$ also retains some characteristics of religious $\mathrm{Bu} \mathrm{Xu} \mathrm{Ci}$ in the artistic feature, and refines it on this basis. It focuses on words and antithesis, rhymes in couplet and readability, so as to harmonize the music and dance and become convenient for Taoist to remember and spread the religion. At the same time, wording and phrasing use allusions, implicit and euphemistic with quite lucid and elegant style. It can be called masterpiece among the poetries of poets in the Tang Dynasty. It can be seen that his wording and phrasing not only use allusions, but also carry out refining. Tu Longping once commented, "There are few poets for $\mathrm{Bu} \mathrm{Xu} \mathrm{Ci} \mathrm{since}$ ancient times. In the three hundred years of the history of Tang dynasty, only Cao Yaobin can make Bu Xu Ci but still can not 
be so tactful." [2] Indeed, Yu Xin's Bu Xu Ci has euphemistic and styles full of twists and turns.

Yu Xin's Bu Xu Ci skillfully used Taoist classics, but expressed his own emotion. The theme expressed by him was more profound than that of the religious $\mathrm{Bu} \mathrm{Xu} \mathrm{Ci}$, closer to the literati's life, focusing on the decoration on art, with more literary temperament. All these have a significant impact on the independence of poetic form of $\mathrm{Bu} \mathrm{Xu} \mathrm{Ci}$.

\section{The INFLUENCE OF YU XIN'S "BU XU CI" ON LITERATI'S TAOISM WORKS}

\section{A. The Expansion of Themes}

The $\mathrm{Bu} \mathrm{Xi} \mathrm{Ci}$ created by the traditional Taoist is the rhyme lyrics used in Taoist rituals, which retains a lot of Taoist culture. When the literati entered into the Taoist temple through $\mathrm{Bu} \mathrm{Xu} \mathrm{Ci}$, these literati's ideas were also brought into the Taoism field, which greatly expanded the theme of Taoist literature and promoted the improvement of Taoist literature and art. Overall, after $\mathrm{Yu}$ Xin's $\mathrm{Bu} \mathrm{Xu} \mathrm{Ci}$, the religious nature of Taoist literature created by literati in selection of the theme is gradually weakened, and the literariness becomes stronger and showing a tendency of routinization and secularization.

As a kind of literary genre of Taoist ritual literature in the Northern Dynasties, Yu Xin's $\mathrm{Bu} \mathrm{Xu} \mathrm{Ci} \mathrm{has} \mathrm{the} \mathrm{religious}$ characteristics to express Taoist thought: describe fairy fantasy, spread the fairy story, create illusory mood, and express the admiration for the immortal. But its original meaning is to introduce the political factors and personal feelings to $\mathrm{Bu} \mathrm{Xu}$ Ci. "The elegant and magical beauty of the immortals" is not been highlighted and the immortal ideal has also been relegated to the second place. The description of the immortal stories derived from the traditional books gets rid of the immortal frenzy; single religious enthusiasm gives place to the light pursuit of ideal realm; the pure religious fantasy pictures change into a poetic and intriguing literary mood. All these finally reflected as the deep and elegant artistic style. He extracted the material from the familiar clan culture, and created a new text different from the Taoism, which laid a kind of cultural character for the literati's Taoist literature creation, and influenced the development direction for the late Qing $\mathrm{Ci}$, $\mathrm{Nv}$ Guan $\mathrm{Ci}$ and other Taoist literary genres.

A new kind of Taoist ritual literary genre emerged in the Tang Dynasty - Qing Ci. Qing Ci, also known as Lv zhang, is the memorial and praying for gods by Taoist in sacrificial ritual activities. It is a written form of expression for communication between man and God. As the main creative subject for the existing Qing $\mathrm{Ci}$, during the creative process, the literati borrowed and expanded the expression field of $\mathrm{Yu}$ Xin's $\mathrm{Bu} \mathrm{Xu} \mathrm{Ci,} \mathrm{not} \mathrm{only} \mathrm{having} \mathrm{the} \mathrm{basic} \mathrm{functions} \mathrm{of} \mathrm{Taoist}$ rituals to communicate with God, avoiding disaster and blessing, but also expressing his yearning for the reclusive life, his ridicule and joke about the politics in reality and his leisurely and carefree mood in everyday life. Qing $\mathrm{Ci}$ combined the interpretation of Taoist doctrine, expression of immortal belief, expression of personal emotion and increasingly strong literary color together, promoted the development of Taoist ritual literature in the direction of literati and routinization.

Nv guan is female Taoist, emerged in Tang Dynasty, believing in Taoism and leaving home to live in Nv guan yuan. Some of these $\mathrm{Nv}$ guan poetesses practice with concentration, cleanse their hearts and limit their desires, conduct devout meditation. Their poems expressed the extraordinary refined ideal, singing the joy of self-adaptation, with quite refined and nonaggressive Taoist interests, so it was named "Hui Zhen Poem". But most of them have open mind, rich feelings and literary talent. They have the courage to express their feelings in poetic works. They have a lot of communications and interactions with scholars on literature, although their bodies were in the Taoist temple, their hearts were often rolling in the mortal world, therefore, the mainstream of their poems are the description of romance, lovesickness and the works in the interaction with the scholars. Obviously, although most of the Nv guan poetesses of the Tang Dynasty are in the Taoist temple, their hearts are in the secular and they have more contact with the literati, thus showing a clear trend of literati and secularization. In the Tang Dynasty, the themes of the $\mathrm{Nv}$ guan works expanded from the small boudoir to the vast real world, or broke through the purdah, into the nature, and even the involved the social reality, commented on the current affairs and concerned about country and people; or lashed the standard of women teaching, expressed the strong love between men and women. On the basis of the politicization and personalization of $\mathrm{Yu}$ Xin's $\mathrm{Bu} \mathrm{Xu} \mathrm{Ci}$, they expressed their emotions more broadly and boldly, expanding the themes of Taoist literature to a broader field.

\section{B. The Improvement of Artistic Level}

As mentioned above, "Ten Taoist $\mathrm{Bu} \mathrm{Xu} \mathrm{Ci"} \mathrm{as} \mathrm{a} \mathrm{Taoist}$ ritual literature created by literati, it made great emphasis on the use of artistic skills, neat sentence, harmonious rhythm, gorgeous language, delicate metaphor ... showing a significant literati tendency. It is a unique style in Taoist ritual literature in Northern Dynasties, greatly opened up the space of literati's Taoist creation later in art skill.

1) Poetic style expansion: $\mathrm{Yu} \mathrm{Xin}$ 's $\mathrm{Bu} \mathrm{Xu} \mathrm{Ci}$ appears as a five-word sentence, neat and rhyme. After that, $\mathrm{Bu} \mathrm{Xu} \mathrm{Ci}$ developed along the direction of $\mathrm{Wu} \mathrm{Gu}$ and $\mathrm{Wu} \mathrm{Lv}$, such as the Bu Xu Ci of Wei Qumou, Wu Yun and Xu Xuan in Tang Dynasty. In addition, the neat seven-word style also appeared. Liu Yuxi, Chen Yu, Su Yu and Gao Pian's works are all seven-word quatrain while Chen Tao is seven-character octave. The number of sentence for each poem is still relatively free without any fixed pattern. The articipation of poets in $\mathrm{Bu} \mathrm{Xu} \mathrm{Ci} \mathrm{makes} \mathrm{this} \mathrm{poetic} \mathrm{style} \mathrm{pay} \mathrm{more} \mathrm{attention}$ to techniques, and gradually move closer to rules and forms. All the styles coexisted in the world and developed together.

2) Use of antithesis: $\mathrm{Yu}$ Xin's $\mathrm{Bu} \mathrm{Xu} \mathrm{Ci}$ focuses on the use of antithesis and tone pattern in order to harmonize the rhythm. The Qing Ci created by literati in Tang Dynasty is directly affected by it. They use the parallel style with excellent words rhyme, with neat antithesis and gorgeous rhetoric, not only showing the author's talent, but also good to 
read and listen. The language form of antithesis makes the ritual Qing Ci rich and colorful.

3) Innovation of allegorical description: In $\mathrm{Bu} \mathrm{Xu} \mathrm{Ci}, \mathrm{Yu}$ Xin skillfully used literary allusions to highlight the theme and expressed his views of society and life. The Qing $\mathrm{Ci}$ in Tang Dynasty is also influenced by it. The allusions used by it often come from the literary classics or classics with strong literariness. Qing $\mathrm{Ci}$ in Taoist rituals often used ancient sacrifice poems. After enrichment and alteration, the content of Qing Ci is full of literature sense. The allusions in Nv Guan $\mathrm{Ci}$ are more flexible and skillful, so that the poem connotation is rich with profound implication, affording food for thought and producing a good lyrical effect. The allusions selected in Nv Guan poems rarely had the majestic atmosphere, but most of them had gentle sentimental female color, expressed the love of the lover, or expressed the plaintive lingering thoughts.

4) The use of rhetorical devices: Compared with the other Taoist ritual literature during the Northern Zhou Dynasty, Yu Xin 's $\mathrm{Bu} \mathrm{Xu} \mathrm{Ci}$ was more sophisticated in the use of rhetorical devices, showing a clear tendency of literati. Since then the literati $\mathrm{Bu} \mathrm{Xu} \mathrm{Ci,} \mathrm{Qing} \mathrm{Ci}, \mathrm{Nv}$ Guan $\mathrm{Ci}$ all followed this to develop. The Qing Ci in Tang Dynasty focused on the use of literary rhetoric devices, used beautiful words to decorate sentences, such as Du Guangting's "Mo Tingyi Weianfu Zhangfushi Shengrizhoutian Niangci": "Xiang za xi yun, deng he ling yue". It associates the misty and indistinct clouds and the bright and hazy moon above the mountain according to the two ritual items namely the incense and lamp used in Taoism ceremony, which was natural and greatly enhanced the the poetic quality.

After the Northern Dynasties, the literati $\mathrm{Bu} \mathrm{Xu} \mathrm{Ci}$ followed the path of $\mathrm{Yu}$ Xin and used the literary skills to strengthen the artistry more consciously in imitating the interest of immortal and religious function described in $\mathrm{Bu} \mathrm{Xu}$ $\mathrm{Ci}$. Together with the Qing ci and Nv Guan ci, they try to slough the boring religious theories, step by step transfer it to the center of title play and lyrical aspiration, thus expanding the expression field and emotional connotation of Taoist literature and contributing to the changes and new ideas of the creation tendencies and styles of some literati.

\section{CONCLUSION}

Taoist unique literati $\mathrm{Bu} \mathrm{Xu} \mathrm{Ci}$ was founded from $\mathrm{Yu}$ Xin's "Ten Taoist $\mathrm{Bu} \mathrm{Xu} \mathrm{Ci"} \mathrm{in} \mathrm{the} \mathrm{Northern} \mathrm{Zhou} \mathrm{Dynasty.}$ Although the origin is the Taoism $\mathrm{Bu} \mathrm{Xu}$, it reflects the creation feature of literati. In $\mathrm{Bu} \mathrm{Xu} \mathrm{Ci}, \mathrm{Yu}$ Xin skillfully used the Taoist classics, yet expressed his own emotion, so the themes of it were more profound than that of the religious $\mathrm{Bu}$ $\mathrm{Xu} \mathrm{Ci}$ and closer to the literati's life. In art, he paid more attention to decoration with more literary temperament. He not only created the precedent of literati $\mathrm{Bu} \mathrm{Xu} \mathrm{Ci}$, but also had a wide and far-reaching impact on the creation of Taoist works. After Yu Xin's Bu Xu Ci, the themes selected in the Taoist literature created by literati were weakened in religion and strengthened in the literariness, showing a tendency of routinization and secularization. At the same time, the literati more consciously expanded the style of poetry, paid attention to the use of antithesis, skillful use of literary allusion and rich rhetoric techniques to enhance the literariness, greatly improving the artistic level of Taoist ritual literature, expanding and deepening the form of literature filed and ideological connotation.

\section{REFERENCES}

[1] (Northern Zhou) Yu Xin, (Qing) Ni Fan Note. Yu Zi Shan Ji Zhu. Beijing: Zhonghua Book Company, 1980: 394, 393, 401, 392, 400, 399, 400, 399, 401.

[2] Sibucongkan Chubianjibu - Yu Zi Shan Ji. Shanghai: Shanghai Commercial Press, Indentation of the Tu Long edition in Ming Dynasty, 1929: 28.

[3] Zhu Yueli. Daozang Fenlei Jieti [M]. Beijing: Huaxia Press, 1996.

[4] Zhengtong Daozang [M]. Taipei: Arts and Literature Press, 1977.

[5] Chen Guofu, Daozang Yuanliu Kao [M]. Beijing: Zhonghua Book Company, 1949. 